\title{
SSinteza
}

Impact of Internet on Business Activities

\section{PRIMJER OTKRIVANJA MANIPULISANJA BAZOM PODATAKA JEDNE VRSTE RAČUNOVODSTVENOG SOFTVERA UZ POMOĆ ALATA DIGITALNE FORENZIKE}

\author{
Nataša Simeunović \\ Fakultet za poslovnu ekonomiju, Univerzitet Sinergija, Bijeljina, BiH
}

\begin{abstract}
:
Sklonost da oblikuje finansijske izvještaje u skladu sa svojim ciljevima uglavnom podstiče menadžment da odstupi od međunarodnih i nacionalnih propisa, te primjeni mjere kreativnog računovodstva koje dovode do neistinitih (lažnih) bilansa. Uključivanje informacionih tehnologija u sve pore savremenog poslovanja razvilo je mogućnosti njihove (zlo)upotrebe u širok dijapazon modaliteta. Kriminalitet koji se realizuje pomoću kompjutera može imati oblik bilo kog od tradicionalnih vidova kriminaliteta kao što su krađe, utaje i pronevjere. Takođe, sticanje protivpravne koristi se može ostvariti i upotrebom neovlašćeno pribavljenih podataka zloupotrebljavajući slabosti informacionih sistema što je uslovilo upotrebu digitalne forenzike u otkrivanju mogućih računovodstvenih manipulacija kao pomoć forenzičkom računovođi koji ima zadatak da otkrije i istraži sve sumnjive ekonomske transakcije koje se mogu okarakterisati kao kriminalne radnje, odnosno rezultirati sudskim sporom primjer čega će biti prikazan u radu.
\end{abstract}

\author{
Key words: \\ forenzičko računovodstvo, \\ forenzička revizija, \\ kompjuterski kriminal, \\ prevare, \\ digitalna forenzika.
}

\section{UVOD}

Savremeno doba digitalizacije podataka ponudilo je nove mogućnosti za počinioce finansijskih prevara, ali i za njihove istražitelje. Modernizacija poslovnih procesa je na mnogo načina promijenila način na koji se sprovodi istraga, metode koje interni revizori koriste za planiranje i obavljanje posla, kao i pristupe koje koriste eksterni revizori da procijene rizik i izvrše reviziju. Sa razvijanjem računovodstvenih softvera, javila se i potreba za primjenom alata digitalne forenzike $\mathrm{u}$ istrazi i obezbjeđivanju dokaza o kriminalnim radnjama u finansijskim izvještajima putem prikupljanja i obrade dokaza pohranjenih na računaru ili nekom drugom nosiocu digitalnih podataka, a vezanih za određenu vrstu nelegalne aktivnosti. U ovom radu, biće objašnjena mogućnost nesmetanog pristupa bazi podataka jedne vrste računovodstvenog softvera kakav se najčešće koristi u prikazivanju poslovanja mikro i malih preduzeća u Republici Srpskoj.

\section{GREŠKE I PREVARE KAO UZROCI NETAČNIH FINANSIJSKIH IZVJEŠTAJA}

Netačni finansijski izvještaji pružaju pogrešnu sliku o prinosnom i/ili finansijskom položaju preduzeća. Odluke koje investitori i drugi korisnici finansijskih izvještaja donose na osnovu pogrešnih finansijskih informacija nanose štetu njihovim interesima stoga je jasan interes sveukupne računovodstvene javnosti da informacije prezentirane $\mathrm{u}$ finansijskim izvještajima prikazuju stvarnu sliku finansijskog i prinosnog položaja preduzeća. Ta stvarna slika će izostati ako u procesu izrade budu učinjene greške ili ako menadžment i sastavljači finansijskih izvještaja žele putem prevare da ostvare koristi na štetu korisnika finansijskih izvještaja, investitora prije svega. Iako su im posljedice iste - nastanak netačnih finansijskih izvještaja, između grešaka i prevara postoje značajne razlike na koje je važno ukazati, prije svega zbog načina njihovog otkrivanja, ali i sankcionisanja.

Ključna odlika grešaka je odsustvo namjere ${ }^{1}$ da se u finansijski izvještaj unese pogrešan podatak, izostavi neki iznos ili objavljivanje. Uobičajene greške obuhvataju one [1]:

- koje nastaju pri prikupljanju dokumentacije ili pri njenoj obradi u postupku izrade finansijskih izvještaja,

- nerazumne računovodstvene procjene koje vode precjenjivanju činjenica ili pak pogrešna interpretacija činjenica,

1 Problem koji se javlja pri davanju odgovora na pitanje da li je neka netačnost posljedica greške ili prevare je u tome što se namjera, a time i odsustvo namjere teško utvrđuje. Primjera radi, nerazumno visok iznos otpisa spornog potraživanja može biti posljedica greške jer nije postojala namjera da se pretjeranim otpisivanjem doprinese iskazivanju nižeg dobitka, no isti postupak bi bio korišćen i kada bi takva namjera postojala. 
- koje nastaju pogrešnom primjenom računovodstvenih principa u vezi sa iznosima, vrstama i načinom prezentacije ili objavljivanja.

Neophodno je reći da greške čine lica koja učestvuju u procesu prikupljanja i obrade informacija koje su osnova za izradu finansijskih izvještaja i lica koja pripremaju finansijske izvještaje, a ne menadžment preduzeća. Prevare $^{2}$, za razliku od grešaka, se sastoje u osmišljenom i namjernom pripremanju dokumenata, činjenica, informacija i situacija da bi se stvorili preduslovi da se neko na bazi pogrešnog predstavljanja činjenica u osmišljenim situacijama i okolnostima, podstakne da povjeruje u neistinu i u skladu sa njom da se ponaša i prema tome, trpi gubitak ili štetu [9]. One se po pravilu zasnivaju na sljedeća četiri osnovna elementa [10]:

1 lažna prezentacija činjenica koje imaju značajan karakter,

2. svijest počinioca o tome da je predstavljanje lažno ili ispoljavanje potpune nemarnosti za istinu,

3. lice koje prima informaciju tretira je kao pouzdanu i oslanja se na nju pri donošenju odluke,

4. zahvaljujući prethodno navedenom nastaju finansijske štete, a koje snose korisnici informacija.

Lažna prezentacija činjenica koje su po svojoj prirodi značajne može se postići manipulacijama, falsifikovanjem ili izmjenama bilo knjigovodstvenih evidencija, bilo knjigovodstvenih dokumenata na osnovu kojih se sastavljaju finansijski izvještaji. Počinioci su svjesni nedopustivosti postupaka i zbog toga se ova djela označavaju kao namjerna.

Za razliku od grešaka, $u$ preTabela 1. Karakteristike forenzičke revizije

\begin{tabular}{|c|c|c|}
\hline $\begin{array}{l}\text { Karakteris- } \\
\text { tike }\end{array}$ & Nezavisna revizija & Forenzička revizija \\
\hline Cilj & $\begin{array}{l}\text { Istraživanje mišljenja o istinito- } \\
\text { sti } i \text { „fer" prezentaciji finansi- } \\
\text { jskih izvještaja }\end{array}$ & $\begin{array}{l}\text { Utvrđivanje i otkrivanje kriminalnih } \\
\text { radnji u finansijskim izvještajima }\end{array}$ \\
\hline Tehnike & $\begin{array}{l}\text { Metode uzorkovanja i } \\
\text { izvođenje kontrolnih i } \\
\text { suštinskih testova }\end{array}$ & $\begin{array}{l}\text { Suštinsko, detaljno i dubinsko provjer- } \\
\text { avanje svih, ili tačno odabranih } \\
\text { transakcija u sumnjivim područjima } \\
\text { poslovanja }\end{array}$ \\
\hline Period & $\begin{array}{l}\text { Ispitivanje finansijskih } \\
\text { izvještaja, transakcija i računa } \\
\text { za određeni vremenski period }\end{array}$ & $\begin{array}{l}\text { Nema takvih ograničenja. Izvještaji, } \\
\text { transakcije i računi mogu biti, po } \\
\text { potrebi, ispitani od početka, „od kor- } \\
\text { jena“, bez obzira na datum događaja }\end{array}$ \\
\hline $\begin{array}{l}\text { Izvještaj i } \\
\text { mišljenje }\end{array}$ & $\begin{array}{l}\text { Izražavanje mišljenja sa } \\
\text { rezervom ili bez rezerve, } \\
\text { uzdržavajućeg ili negativnog } \\
\text { mišljenja }\end{array}$ & $\begin{array}{l}\text { Izražavanje mišljenja u pogledu } \\
\text { mjesta, vremena i načina izvršenja } \\
\text { kriminalne radnje, obračunavanja } \\
\text { štete i imenovanja počinioca. }\end{array}$ \\
\hline
\end{tabular}
varama se kao počinioci - inspiratori javljaju različiti nivoi uprave uključujući i top menadžment kome se često priključuju i treća lica.

Da bi prevara bila moguća potrebno je da egzistiraju sljedeća tri elementa koja čine tzv. „trougao prevare“ [9]:

- motiv za prevaru (pritisak - Pressure),

- mogućnost (prilika - Opportunity) za prevaru, i

- nedostatak integriteta (racionalizacija - Rationalization).

\section{TRADICIONALNA REVIZIJA VS. FORENZIČKA REVIZIJA}

Za razliku od tradicionalne, nezavisne revizije, koja ima za cilj da formira mišljenje da li su posmatrani finan-

2 Prevare, u širem smislu definisane, obuhvataju: prevare koje nastaju zloupotrebom imovine, korupciju i prevare putem finansijskog izvještavanja. sijski izvještaji sastavljeni u skladu sa opšteprihvaćenim računovodstvenim pravilima i da li predstavljaju u svim materijalno značajnim aspektima fer i istinitu finansijsku poziciju klijenta, forenzička revizija predstavlja posebnu uslugu nezavisne revizije sa ciljem da otkrije kriminalne radnje u finansijskim izvještajima, bez obzira na veličinu njihove materijalnosti, $\mathrm{i}$ iste predstavi na način prihvatljiv za sudski postupak.

Forenzička revizija zahtijeva angažovanje profesionalaca u reviziji koji su prošli posebne obuke i posjeduju iskustvo u borbi protiv kriminalnih radnji. Moramo napomenuti da forenzička revizija predstavlja jednu od usluga koju izvode forenzičke računovođe.

Većina teoretičara i praktičara forenzičkog računovodstva u svijetu ističu da forenzičko računovodstvo obuhvata dva široka područja: istražno računovodstvo, u okviru kojeg se nalazi i forenzička revizija, i sudsku podršku.

Razlike između nezavisne revizije i forenzičke revizije, prema Petkoviću [6], su prikazane u tabeli 1. 
postoji. Ovim indicijama i događajima treba pridodati, zbog gotovo jednakog značaja, i one koje potiču iz okruženja. Tokom godina, kako su informacione tehnologije uzimale sve veće učešće u poslovnim procesima, mnogi su standardi pokušavali regulisati njihovu primjenu u cilju poboljšanja sposobnosti softverskih procesa i uticanja na povećanje zrelosti organizacija. Razvoj softvera u različitim oblastima pratio je razvoj standarda, procedura, metoda i alata za razvoj i upravljanje softverom [5]. No, kako stvari na tržištu softvera stoje, može se reći da smo još daleko od poželjnog nivoa njihovog kvaliteta.

Nacionalni standard baziran na međunarodnim standardima kojim su se pokušali definisati elementi kvaliteta računovodstvenog softvera kao i osnove za utvrđivanje metoda i načina ocjene kvaliteta i/ili atesta računovodstvenog softvera jeste JRS 33 - Jugoslovenski računovodstveni standard Računovodstveni softver koji je nastao sredinom devedesetih godina. U njemu su posebno razmatrana tri odvojena aspekta: eksterni zahtjevi, interni zahtjevi od strane softverskih kuća i korisnički zahtjevi. No, njegova primjena nije zaživjela.

Pri pronalaženju dokaza koji potvrđuju postojanje prevara koje su počinjene korišćenjem računara pomaže nam digitalna forenzika.

Moramo napomenuti da u procesima zvanične istrage tehnikama digitalne forenzike, prikupljanja, analize i prezentacije digitalnih dokaza potrebno je pridržavati se određenih principa koji određuju proces upravljanja digitalnim dokazima. Ti principi treba da [5] :

- budu konzistentni sa svim legalnim sistemima,

- dopuštaju korišćenje s uobičajenim jezikom,

- budu trajni i međunarodno prihvatljivi,

- ulivaju povjerenje i obezbjeđuju integritet digitalnih dokaza,

- budu primjenljivi na sve vrste digitalnih dokaza,

- budu primjenljivi na svim nivoima, od pojedinca, preko zvaničnih agencije, do najvišeg nacionalnog nivoa.

\section{DIGITALNA FORENZIČKA ISTRAGA MANIPULACIJE RAČUNOVODSTVENOG PROGRAMA}

Danas, dva vodeća softverska paketa u digitalnoj forenzici su EnCase, firme Guidance Software i Forensic Toolkit (FTK), firme AccessData. Ova programska rješenja omogućavaju brže savladavanje tehnika digitalne forenzike, jer na jednom mjestu objedinjuju veći broj zadataka za koje bismo inače koristili više različitih forenzičkih alata. U posljednjih nekoliko godina alati bazirani na Linux platformi često se koriste. Ova rješenja su postala popularna jer predstavljaju besplatnu alternativu sa svim funkcionalnostima komercijalnih rješenja. Helix, the Penguin Sleuth i BackTrack su Linux distribucije koje se pokreću direktno sa CD-a pružajući čisto okruženje za istragu, bez potrebe za kloniranjem sistema. Ovi alati pokreću Linux sistem sa CD-a, a hard diskove računara učitavaju u režimu za čitanje zaobilazeći većinu lozinki i bezbjedonosnih zaštita. Glavna mana Linux rješenja je u njihovoj kompleksnosti kao i u slaboj podršci. Takođe, dostupni su specijalizovani alati koji su usmjereni na otključavanje lozinki i vraćanje obrisanih fajlova [8].

Analizom protokola i mehanizama koji se koriste na aplikaciji za knjiženje utvrđeno je da postoji mogućnost pristupa sa udaljene tačke na bazu podataka računovodstvenog programa. Kao najveća slabost identifikovano je čuvanje podataka u otvorenoj bazi podataka pod kojom podrazumijevamo baze čijim podacima se može pristupiti i čiji podaci se mogu izmijeniti a da za to nije potrebna identifikacija kao ni autentifikacija.

Pristupom računaru koji se koristi u računovodstvu sa udaljene tačke utvrđeno je postojanje dijeljenog foldera koji je sadržavao računovodstveni program i bazu podataka. Kako je prikazano na sl. 1, ostvareni pristup dijeljenom direktorijumu računara moguće je iskoristiti za direktnu izmjenu podataka u bazi kao i za preuzimanje baze na udaljeni računar. Ovakav pristup je moguć zbog sigurnosnog propusta u samom kreiranju programa, tj. ne postojanju politike zaštite podataka sadržanih u istom kojom bi se ograničio pristup računaru sa udaljene lokacije. Ova vrsta propusta je napravljena radi postizanja lakše administracije od strane proizvođača softvera čime je, sa druge strane, omogućeno lakše pristupanje bazi i stvaranje više prilika za manipulaciju. U ovoj studiji slučaja baza podataka je preuzeta na računar revizora radi dalje analize.

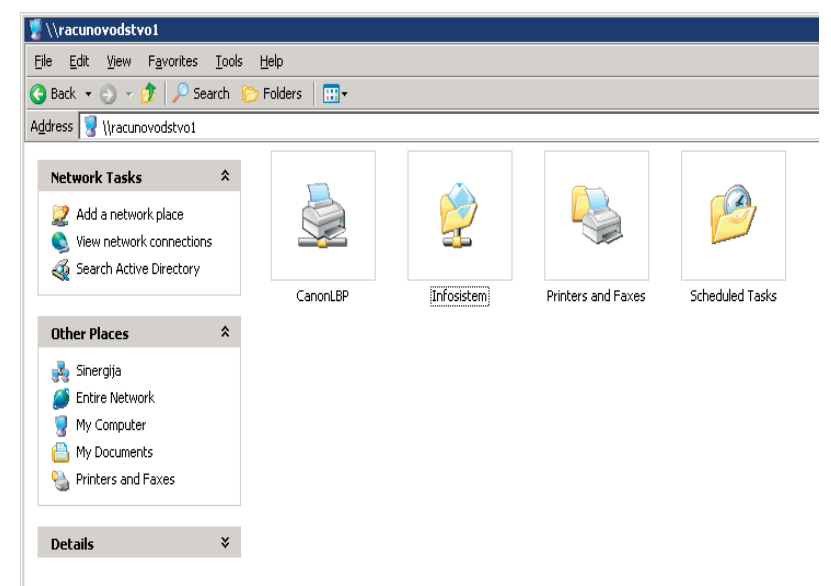

Sl. 1. Pristup dijeljenom folderu

Druga metoda pribavljanja podataka podrazumijeva upotrebu neke od „live“ distribucija Linux-a koja omogućava da istražitelj pregleda datoteke na disku uključujući i izbrisane, bez promjene na disku koji se ispituje. Istražitelj zatim može prekopirati datoteke za koje postoji interes da ih prikaže ili detaljnije ispita. Skriveni podaci najčešće sadrže vitalne dokaze koji mogu dokazati ili opovrgnuti slučaj. Koraci koje treba poštovati tokom pribavljanja i analize dokaza su [3]:

- Nikada ne raditi analizu na prvobitno kreiranom klonu diska, uvijek napraviti dodatnu radnu verziju.

- Prije rada na radnoj verziji treba izvršiti hešovanje verzije, zbog potvrde da nije došlo do promjene u toku istrage.

- Praviti bilješke o svim pronalascima.

- Što češće snimati rezultate zbog potencijalnog gubitka električne energije i gubitka podataka. 
Za potrebe ovog rada za pregled podataka iz baze koja se koristi za računovodstveno knjiženje korišćen je alat DBF Viewer kao što je prikazano na sl. 2.

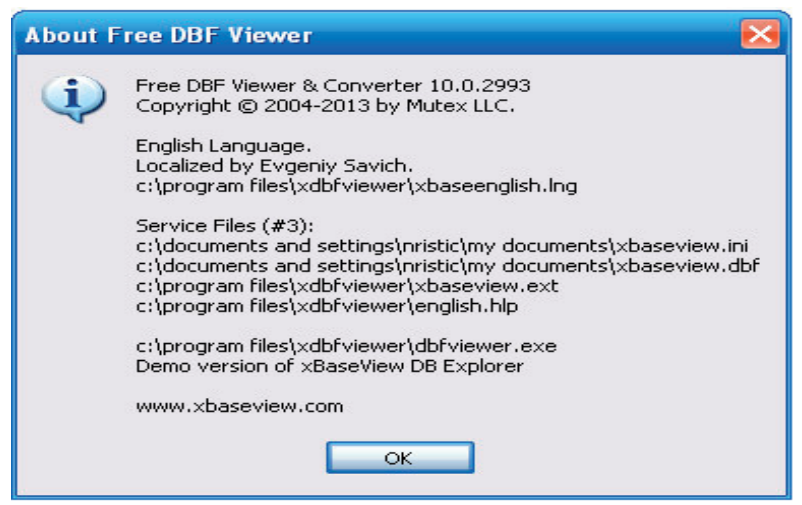

Sl. 2 Alat za pregled podataka u fajlovima .dbf

Prije i tokom forenzičke analize, potrebno je da revizori preduzmu dodatne korake da bi obezbijedili dokaze. Prije forenzičkog pregleda, revizor mora fizički obezbijediti sistem koji ispituje, fotografisati prostoriju, prostor oko sistema i sam sistem. Pored toga, revizor mora obezbijediti dokaze na licu mjesta ili u laboratoriji u kojoj se vrši pregled zbog pravilnog rukovanja dokazima. Revizor, takođe, treba da dokumentuje sve detalje u vezi sistema kao i povezanost sistema putem žične ili bežične mreže.

Određene procedure i postupke, detaljnije opisane u [8], treba maksimalno izbjegavati prije prikupljanja datoteka i kloniranja diska.

$\mathrm{Na}$ sl. 3 se vidi ostvaren pristup i pregled svih unosa u program za knjiženje na primjeru ulaska u bazu faktura za 2012. godinu. Ovakvim pregledom utvrđeno je da se može izvršiti nesmetan pristup kompletnoj bazi kao i mogućnost da se vrše izmjene ili manipulacije nad svim podacima. Preduzeća i organizacija bi morale imati utvr- đene kontrolne procedure kojima pokušavaju spriječiti prevare i malverzacije. Dobra tehnika forenzičke revizije je pokušavanje i pronalaženje slabosti u tim sigurnosnim procedurama i na taj način pronalaženje slabosti u samom sistemu. Slabosti koje se pronađu u okviru kontrole organizacije najvjerovatnije će odvesti do počinioca

U slučaju potreba za pronalaženjem sličnih dokumenata i poređenja nekog postojećeg dokumenta, metoda koja je dala najbolje rezultate je upotreba segmentnog hešovanja iniciranog sadržajem [7]. Ova metoda nudi mogućnost poređenja postojećih fajlova uz identifikovanje indeksa sličnosti. Metoda je uspješno korišćena u analizama podataka iz baze nad kojima je vršena manipulacija. Metod identifikovanja sličnih fajlova i prikaz indeksa njihove sličnosti može ukazati na količinu izvršenih izmjena nad podacima [2].

\section{ZAKLJUČAK}

Inkorporiranje informacionih tehnologija u sve poslovne procese doprinijelo je širenju mogućnosti kojima se, pored ostalih, mogu činiti i računovodstvene prevare. Značaj ovog problema nas je naveo da pokušamo prikazati jedan od mogućih primjera manipulacije koji su mogući u gotovo svim računovodstvenim programima koji se u najvećoj mjeri koriste za prikazivanje poslovanja mikro i malih preduzeća u Republici Srpskoj, a koja čine 94,5\% ukupnog broja registrovanih privrednih društava, zadruga i drugih pravnih lica koja vode dvojno knjigovodstvo i koja su podnijela finansijske izvještaje APIF-u za 2010. godinu prema Pregledu koji izdaje Privredna komora RS.

Zaštiti ovog tipa informacionih sistema (misli se na računovodstveni softver) u Republici Srpskoj, i Bosni i Hercegovini kao cjelini, generalno je posvećena mala pažnja kako od strane proizvođača tako i države. Proizvođači žele

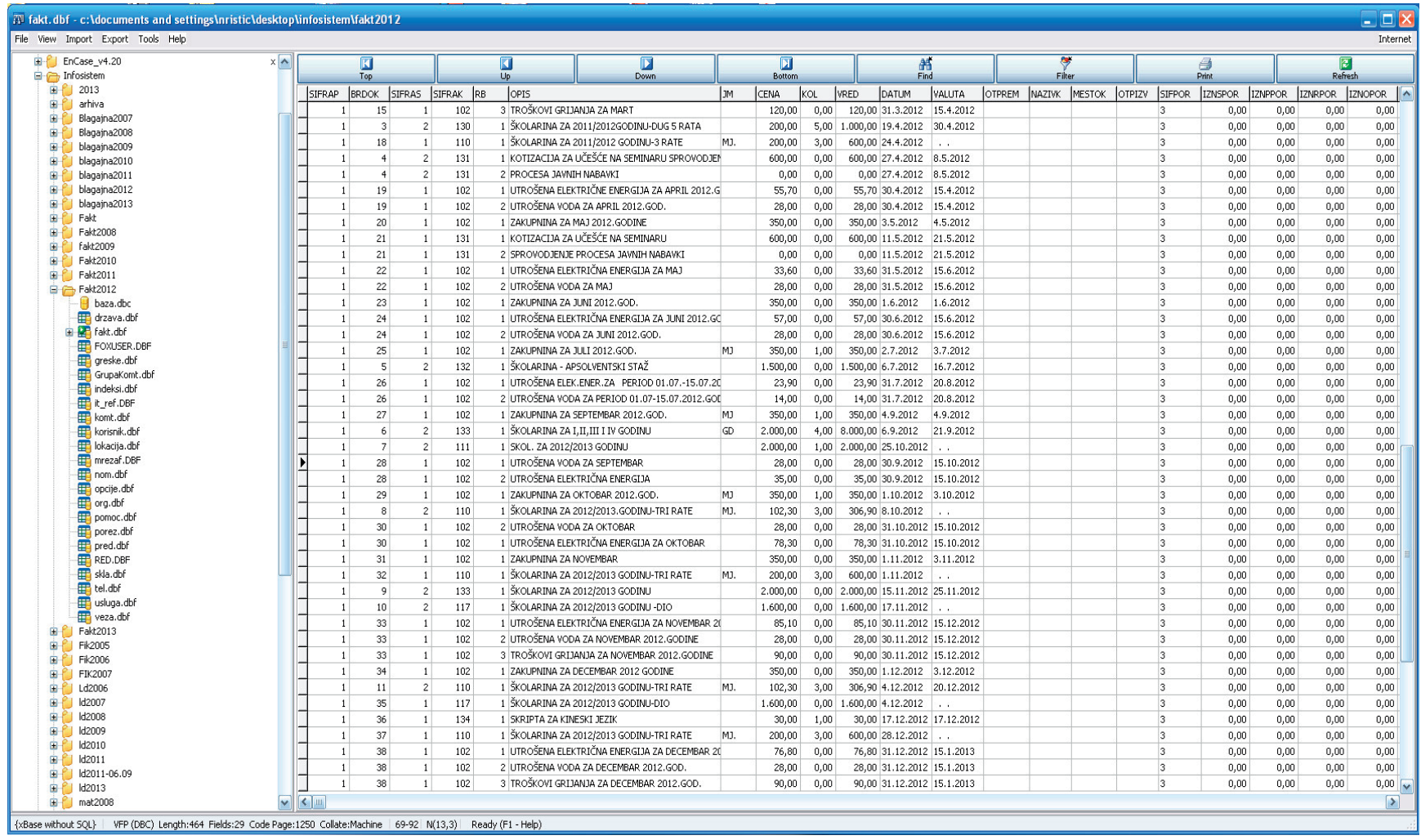

Sl. 3 Forenzička analiza tabele sa podacima knjiženja 
prodati svoj prozvod što većem broju klijenata, a to mogu postići samo ako programi zadovoljavaju potrebe (interese) klijenata i omogućuju im da koriste nedorečenosti zakonskih normi, odnosno nedostatak istih u pogledu zaštite prvobitno unesenih podataka od eksternih i/ili internih napada (upada) u bazu podataka računovodstvenog softvera. Moguće rješenje bi se moglo pronaći u utvrđivanju neophodnosti obaveznog snimanja svih unosa u bazu i obezbjeđivanje nemogućnosti njihove izmjene, bez obzira da li je razlog tome ispravka greške ili namjerna korekcija unosa, bez arhiviranja prethodno unesenih podataka.

Mogućnosti manipulisanja podacima u finansijskim izvještajima, kao proizvodom korišćenja ovih programa, su raznovrsne što može uticati na kvalitet poslovnog ambijenta Republike Srpske, odnosno Bosne i Hercegovine kao države. Gledano s aspekta IT vještačenja, mogućnost utvrđivanja manipulisanja podacima ove vrste je gotovo nemoguće dokazati bez originalnih dokumenata čime put onima koji time stiču korist ostaje i dalje otvoren.

\section{LITERATURA}

[1] Golden, T., Skalak, S., Clayton, M., A Guide to Forensic Accounting Investigation, John Wiley\&Sons, Inc. 2006.

[2] Grubor G., Vićentijević K., Petrović Z., Simeunović N.:"Excel file Financial Fraud Forensic Analysis - Case Study", METALURGIA INTERNATIONAL ISSN 1582-2214, vol. XVIII, no. 10/2013, p. 87-90
[3] http://www.theiia.org/intAuditor/itaudit/archives/2006/ september/computer-forensics-a-valuable-audit-tool-1/; dostupno januar 2013.

[4] Krsmanović, B., „Kvalitet računovodstvenog softvera“, Časopis Finrar, Finrar d.o.o., Banja Luka, 03/07

[5] Milosavljević M., Grubor G., Istraga kompjuterskog kriminala, Univerzitet Singidunum, Beograd, 2009.

[6] Petković A., Forenzička revizija - kriminalne radnje u finansijskim izveštajima, Proleter, Bečej, 2010.

[7] Ristić N., Jevremović A., Veinović M., "Identifikovanje homogenih fajlova upotrebom segmentnog hešovanja iniciranog sadržajem", 20th Telecommunications forum TELFOR 2012, Serbia, Belgrade, November 20-22, 2012, 1665-1668

[8] Simeunović N., Ristić N., "Digitalna forenzika u funkciji forenzičkog računovodstva”, INFOTEH-JAHORINA Vol. 12, March 2013, 1006-1010

[9] Stanišić M., Revizija, Univerzitet Singidunum, Beograd, 2009.

[10] Škarić Jovanović K., „Forenzičko računovodstvo - instrument zaštite interesa računovodstvene javnosti“, Zbornik radova sa 13. Kongresa SRRRS, Banja Vrućica, 2009.god

\section{AN EXAMPLE OF DETECTING MANIPULATION OF A DATABASE OF ONE TYPE OF ACCOUNTING SOFTWARE WITH THE HELP OF DIGITAL FORENSICS TOOLS}

\footnotetext{
Abstract:

The tendency to form financial statements in accordance with its objectives mainly encourages management to deviate from international and national regulations, and implement creative accounting measures that lead to incorrect (false) balances. Implementing information technology in all aspects of modern business brought possibilities to their (mis)use in a wide range of modalities. Crime that is being implemented by computer may take the form of any of the traditional forms of crime such as theft, fraud and embezzlement. Gaining unlawful benefits can also be achieved by unauthorized use of data obtained by abusing weaknesses of information systems which led to the use of digital forensics in the discovery of possible accounting manipulations to help the forensic accountant who has the task to identify and investigate any suspicious economic transactions that can be characterized as fraud or result in litigation example of which is shown in the paper.
}

\section{Key words:}

forensic accounting,

forensic audit, computer crime, fraud, digital forensic. 